\title{
Robotic heart surgery: Hype or hope?
}

\author{
Joseph A. Dearani, MD
}

\author{
From the Department of Cardiovascular Surgery, Mayo Clinic, Rochester, Minn \\ Disclosures: Author has nothing to disclose with regard to commercial support. \\ Received for publication Sept 11, 2017; accepted for publication Sept 15, 2017; available ahead of print Oct 19, \\ 2017. \\ Address for reprints: Joseph A. Dearani, MD, Department of Cardiovascular Surgery, Mayo Clinic, 200 First St, \\ SW, Rochester, MN 55905 (E-mail: jdearani@mayo.edu). \\ J Thorac Cardiovasc Surg 2018;155:77-8 \\ $0022-5223 / \$ 36.00$ \\ Copyright (C) 2017 Published by Elsevier Inc. on behalf of The American Association for Thoracic Surgery \\ https://doi.org/10.1016/j.jtcvs.2017.09.063
}

The application of robotics in cardiac surgery has not been widely embraced, and only a few centers use it with regularity. Robotic assistance is used mostly for mitral valve repair and, to a lesser extent, with coronary surgery, closure of simple septal defects, tricuspid valve repair, and cardiac tumor removal. Gillinov and colleagues ${ }^{1}$ are to be congratulated on this analysis of their early results of their first 1000 robot-assisted mitral valve surgery cases.

Strengths of this study include the high volume of cases, the high success rate of mitral repair (98\%), and low early mortality $(<1 \%)$. Importantly, the authors used standardized mitral repair techniques (ie, posterior leaflet resection, anterior leaflet artificial chords or chordal transfer, and posterior annuloplasty band support). The importance of reproducing the gold standard approach to mitral repair robotically cannot be overemphasized because the reproduction of these techniques with the robot in an effective and efficient manner is not easy. In this experience, cardiopulmonary bypass and crossclamp times decreased over time as did need for conversion to an open procedure. Similarly, the need for blood transfusion and length of hospital stay decreased as their experience progressed. Finally, they developed a standardized approach to patient selection that also evolved throughout their experience. The importance of preoperative computed tomography imaging to examine aortic and peripheral vasculature, in addition to echocardiographic determination of the degree of aortic regurgitation, ventricular function, and so on, to insure the selection of low-risk patients appears to have contributed substantially to the good results they achieved. This is perhaps the most important message of this article...choose patients carefully who have a high probability of success. Appropriate patient selection is essential for surgeons and institutions considering a robotics program in cardiac surgery. Surgical teams need to set themselves up for victory, particularly early in their experience, and consider standard open repair approach for more difficult cases (ie, more challenging cardiac pathology, previous cardiac surgery, larger body habitus, and so on).

Limitations of this review include the lack of follow-up echocardiographic data beyond hospital discharge.

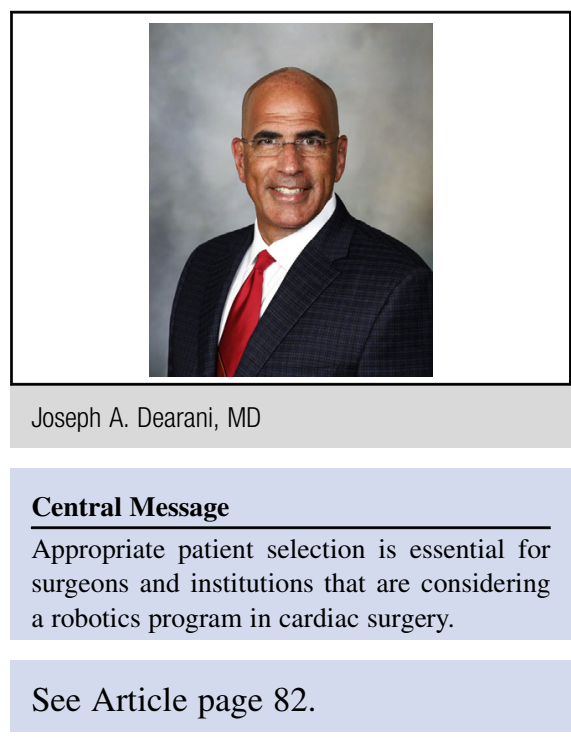

Although not the intent of this review, confirmation of valve durability at the 1- and 5-year postoperative time points would have strengthened the argument of effectiveness of the robotic approach. Because Gillinov and colleagues ${ }^{1}$ have applied standard valve repair techniques and have not taken shortcuts or compromised by performing a "lesser" operation (eg, applying eccentric suture annuloplasty as opposed to band placement) it is reasonable to assume that valve durability should be similar to that achieved by open mitral repair. ${ }^{2,3}$ The relatively high initial stroke rate of $2 \%$ in the first 500 patients decreased to $0.8 \%$ in the second 500 patients after implementation of routine preoperative computed tomography scanning of chest, abdomen, and pelvis to exclude atherosclerotic disease. This refinement in patient selection, as well as the systematization of their intraoperative technique of aortic manipulation, occlusion, and cardioplegic administration, contributed to their outcome improvement.

However, there are additional subtle nuances from this report that deserve comment. The author's institution has an established track record with mitral valve repair in a large number of patients over many decades. As a result, the teams that performed these operations were led by "experienced" mitral repair surgeons who had complete command of the open mitral repair operation; their learning curve focused on mastering robotic technology and process improvement initiatives. Their previous surgical experience with mitral valve repair undoubtedly contributed to a more rapid recognition of ways to reconcile untoward early findings (eg, high early stroke rate in a relatively young and otherwise healthy population that was often asymptomatic). 
It will be difficult for most programs to duplicate the authors' facility with robotic mitral valve repair. In the larger practice of cardiac surgery in the United States, the median number of mitral operations performed was 5 per year, ${ }^{4}$ so most surgeons will see a relatively small number of patients, which makes application of robotic technology to mitral valve surgery an unrealistic expectation for most operators.

Finally, the optics and visualization obtained with robotic procedures is one of the best teaching tools in terms of seeing details of the various repair procedures. This important educational element of the robot is often not appreciated or emphasized and could contribute to the successful learning of mitral repair techniques to the broader surgical community. On the other hand, open mitral repair is a case that an attending can typically help a resident do...so while the improved visualization is instructive to residents and the entire team who can now see everything, it is unlikely that a resident will get to do a robotic mitral repair during training. At present, robot-assisted cardiac surgery is an effective less invasive, cosmetically favorable approach for performing gold standard repair techniques that are identical to the accepted open techniques. Other advantages of robotics include a short length of hospital stay and reduced need for blood transfusions. ${ }^{2,3}$ The advantages of robot-assisted mitral repair versus sternotomy seem clear. Future studies should examine the added value of robot-assistance compared with the thoracoscopic mini-thoracotomy approach. ${ }^{5}$

\section{References}

1. Gillinov AM, Mihaljevic T, Javadikasgari H, Suri RM, Mick SL, Navia JL, et al. Early results of robotically assisted mitral valve surgery: analysis of the first 1000 cases. J Thorac Cardiovasc Surg. 2018;155:82-91.e2.

2. Suri RM, Dearani JA, Mihaljevic TM, Chitwood WR Jr, Murphy DA, Trento A, et al. Mitral valve repair using robotic technology: safe, effective, and durable. J Thorac Cardiovasc Surg. 2016;151:1450-4.

3. Suri RM, Thompson JE, Burkhart HM, Huebner M, Borah BJ, Zhuo L, et al. Improving affordability through innovation in the surgical treatment of mitral valve disease. Mayo Clinic Proc. 2013;88:1075-84.

4. Bolling SF, Li S, O'Brien SM, Brennan JM, Prager RL, Gammie JS. Predictors of mitral valve repair: cinical and surgeon factors. Ann Thorac Surg. 2010;90: 1904-11.

5. Suri RM, Schaff HV, Meyer SR, Hargrove WC III. Thoracoscopic versus open mitral valve repair: a propensity score analysis of early outcomes. Ann Thorac Surg. 2009;88:1185-90. 